\title{
Renewable Resources: Theme with Broad Societal Impact for REU Students
}

\section{Dr. Susan L. Burkett, University of Alabama}

Dr. Susan L. Burkett earned the B.S., M.S., and Ph.D. degrees in Electrical Engineering from the University of Missouri in Columbia, Missouri in 1985, 1987, and 1992, respectively. She joined the University of Alabama in 2008 as the Alabama Power Foundation Endowed Professor in Electrical and Computer Engineering. From 2005 to 2007, she served as program director at the National Science Foundation in the Division of Undergraduate Education. Her research interests are in the areas of electronic materials and methods to offer support for student success. Dr. Burkett is a senior member of IEEE, a Fellow of the AVS: Science and Technology Society, and a member of the ASEE Women in Engineering Division.

\section{Sally Gerster, University of Colorado}

Sally Gerster is a senior in Architectural Engineering at the University of Colorado Boulder and plans to graduate with a combined BS/MS degree in May 2019. She studied abroad at the National University of Singapore for one semester. Sally has been a part of Bridges to Prosperity - CU Chapter, and helped build a footbridge in the Andes of Bolivia with a team of CU students in summer 2016. In summer 2017 she participated in UA's REU Site: Innovative Engineering Using Renewable Resources. In this program, she worked on a project focusing on Seismic Performance of Bamboo Framing Systems. Currently, Sally is the President of the CU Chapter - Earthquake Engineering Research Institute. In January 2018, she teamed with CU students to use bamboo in rebuilding homes in Ecuador after they were destroyed in the 2016 earthquake.

\section{Dr. Todd Freeborn, University of Alabama}

Todd Freeborn, $\mathrm{PhD}$, is an assistant professor with the Department of Electrical and Computer Engineering at The University of Alabama. His current research focuses on techniques to collect and analyze the electrical impedance of biological tissues and their potential applications.

\section{Dr. Debra Moehle McCallum, University of Alabama}

Debra McCallum is a Senior Research Social Scientist and Director of the Institute for Social Science Research. She received her B.S. in Psychology from Furman University and her M.S. and Ph.D. in Psychology from the University of North Carolina at Chapel Hill. She is a social psychologist interested in evaluations of education and community intervention programs and research on social issues, such as career choices related to STEM fields, social-psychological aspects of health behavior and outcomes, and safety and well-being of children and youth. She has led program evaluation activities for a variety of NSF-funded projects.

\section{Dr. Rachel M. Frazier, University of Alabama}

Rachel helps entrepreneurs plan sustainable businesses as part of her work at the University of Alabama. She is currently the Assistant Director of the Alabama Innovation and Mentoring of Entrepreneurs center on campus. She teaches entrepreneurship, assists faculty with building and testing minimum viable products, and mentors STEM faculty and student teams through customer discovery, technology commercialization, and starting a company. In addition, Rachel started a performance materials company that serves the automotive and coating industries, and she actively encourages and supports women startups. Rachel has a B.S. in Physics (2001) and a Ph.D. (2005) in Materials Science and Engineering from the University of Florida, and was an ASEE sponsored postdoc at the Naval Research Laboratory in Washington, DC (2005-2007).

\section{Dr. Eric R. Giannini, RJ Lee Group}


Eric R. Giannini earned his PhD in Civil Engineering from The University of Texas at Austin in 2012. $\mathrm{He}$ is currently a Principal Investigator at RJ Lee Group, Monroeville, PA. Previously, he was an Assistant Professor at The University of Alabama from 2012 to 2017, where he was co-PI on the NSF REU Site: Innovative Engineering using Renewable Resources (EEC-1559867). His research interests include concrete durability and the mechanical behavior of bamboo. 


\title{
Renewable Resources: Theme with Broad Societal Impact for REU Students
}

\author{
S. L. Burkett ${ }^{\mathrm{a}}$, S. Gerster ${ }^{\mathrm{b}}$, T. J. Freeborn ${ }^{\mathrm{a}}$, E. R. Gianninic, R. M. Frazier ${ }^{\mathrm{d}}$, \\ D. M. McCallum ${ }^{\mathrm{e}}$, and G. Quenneville ${ }^{\mathrm{e}}$
}

\begin{abstract}
Renewable Resources, as our Research Experience for Undergraduates (REU) Site theme, provides a socially relevant context and unifies the student cohort. In our nine-week program, ten students are immersed each year in projects related to renewable resources. They also engage in professional development seminars and a six-week entrepreneurship course (Crimson Startup). Each research project involves investigating various properties of bamboo. Bamboo was chosen based on recent interest in Alabama as a product with potential for economic benefit. Faculty mentors were brought together during the proposal phase of the program to discuss ways of getting involved in bamboo research. Our team's advisory board is invested in marketing, distributing, and commercializing bamboo products. The board includes members of a non-profit group, a small business, and the owner of a bamboo nursery. They provide inspiration and support for our REU Site. Students engage with the board members during a field trip to observe a fully developed bamboo nursery. A student from our 2017 program worked on seismic performance of bamboo framing systems and found an opportunity to work on a project in Ecuador rebuilding homes from bamboo in low-income communities after a disastrous earthquake in 2016.

Assessment of program activities led to improvements in both the professional development and entrepreneurial training aspects of the project. After the first summer, bi-weekly professional development seminars became weekly seminars to give students more time as a cohort and to incorporate some equipment training. Changes in the Crimson Startup course include: adding a half-day orientation to describe the program, assigning a coach to every team, requiring weekly office hours between teams and coaches, and clarification of the business model. In focus group discussions and on questionnaires, students indicated that the renewable resource focus is a very attractive aspect of the REU. The students also expressed appreciation of the social value of renewable resources in general and bamboo specifically. Many were attracted to the REU particularly because of its emphasis on these materials. Evaluation results show that overall, the students have been happy with the program, and there was somewhat improved satisfaction with the Crimson Startup program in the second year. On nine-month follow-up surveys with students from the first year, all students said they would recommend the REU to other students; and students from the second year who completed a survey at the end of the summer all rated the REU experience as "excellent" and said they would recommend it to others.
\end{abstract}

\section{Keywords}

Undergraduate research, entrepreneurship training, socially relevant research theme

\section{Introduction}

The National Science Foundation Research Experience for Undergraduate (REU) programs offer students the ability to gain research experience, engage in professional development opportunities, and interact socially with a community of scholars. REU programs are known for increasing enthusiasm in students for their major and encouraging many to pursue graduate studies [1-3]. Research themes for REU Sites are important in that they provide students with a focused technical area where they can investigate solutions to complex science and engineering problems. Students are enthusiastic about topical areas with potential for broad societal impact because they understand the relevance of critical problems. They want 
to be a part of the solution that impacts humanity, advancing a technology, the environment, etc. We have completed two years of a NSF funded REU site on renewable resources at The University of Alabama (UA). Most of our projects involve using bamboo in various engineering applications. This decision was based on the proximity of a small company that actively pursues engineering products using bamboo and faculty interested in the topic. The company hosts a field trip to their bamboo nursery for our students every summer and participates in our end of summer poster session.

The focus of this paper is on a unique opportunity that occurred after the summer 2017 program. Coauthor, Sally Gerster, worked on evaluating seismic performance of bamboo framing systems. She and another REU student, Emma Burford, worked together to design and build two bamboo frames. Using UA's shake table, the frames were tested to compare lashing connections with gusset plate connections. After Sally returned to her home institution, she discovered the Bahia Beach Construction (BBC) program [4]. BBC, located in Bahia de Caraquez, Ecuador, has three goals: 1) to donate economical and seismically safe houses; 2) to demonstrate sustainable bamboo architecture; and 3) to create local jobs in the green building industry. BBC began in response to an earthquake (magnitude 7.8) that hit the northern coastline of Ecuador on April 16 ${ }^{\text {th }}, 2016$. Bahia de Caraquez was destroyed. What used to be a bustling city is now a ghost town of damaged buildings and empty lots. Since the earthquake, BBC has built 19 bamboo homes with the help of Ecuadorian architects, carpenters, community members, and the university teams that partner with them from all over the U.S.

\section{REU Site Program}

To date, UA has hosted nineteen undergraduates in the program. Faculty and graduate students provide mentoring on socially-relevant projects. Tiered mentoring can be very effective in structured undergraduate research programs [5]. Having multiple levels of supervision is essential in the summer when faculty may be traveling. Of the student participants, $58 \%$ were from groups underrepresented in engineering (female, African American, Hispanic, Pacific Islander) and 37\% were from institutions with limited research opportunities. We define limited research opportunities as institutions that lack graduate programs. Our REU students participated in a six-week course, as part of the UA I-Corps ${ }^{\mathrm{TM}}$ Site, where they learn how to test business hypotheses. The UA course, Crimson Startup, [6] teaches Lean Launchpad $^{\circledR},[7]$ to improve student understanding of entrepreneurship through customer discovery as a way of determining what the market truly values. The students create a video at the end of the program describing their ideas and make recommendations on whether or not they see pursuing their product concepts to be worthwhile. This program was described in a previous publication [8].

\section{Bahia Beach Construction (BBC) Program}

This paper describes a unique opportunity that leverages the experience obtained in a research project for a student participant in the 2017 program. The BBC program provided opportunities for our student to work on a bamboo house with an Ecuadorian Bamboo Architect, Robinson Vega, and Ecuadorian maestros (masters of bamboo). In addition, she gained knowledge about entrepreneurship from BBC's Development Manager, Lucas Oshun. The Crimson Startup program, required in our REU, gave her a headstart into working with bamboo and encouraged a rich international experience. An interesting study [9] found domestic students possessed an improved understanding and appreciation of globalization when participating in a research program in Japan compared to one in the U.S., consistent with rich experiences gained by students participating in study abroad programs. 
Our student's summer experience that involved evaluating seismic performance of bamboo framing systems put her in excellent position of comfort when communicating with the construction personnel in Ecuador. She already understood bamboo properties, how it grows, and how it can be used as a building material due to her mentoring by a faculty member in Civil Engineering at UA. Because of this experience, she was able to discuss many aspects of bamboo with the BBC personnel, ranging from small issues to more global issues that resulted in a sense of how American and Ecuadorian perspectives, regarding bamboo, compare. In the US, not many people know about bamboo and the potential it has both as a building material and in other applications. Several entities in Alabama are promoting bamboo and highlighting eco-friendly features that support sustainability. In Ecuador, bamboo is viewed as a poor man's material because it is considered temporary and is inexpensive. However, when treated, bamboo can be used to construct magnificent buildings that will last just as long as buildings made from traditional materials. BBC strives to break this stigma and educate people on the superior performance of bamboo in terms of resistance to seismic damage. As with all students that study abroad, language can be a barrier. Our student had one semester of Spanish previous to this international experience. Familiarity with bamboo helped her to be proactive in communicating and learning from the architect and builders. She indicated she was much more comfortable in communicating by the end of the visit. She states her favorite moment was during roof construction. She expressed interest in the roof to one of the maestros and he invited her to help. She was instructed how to sit and where to drill and together they bolted the top roof beam to the columns. This gave her a sense of accomplishment and she felt was a defining moment (see photo).

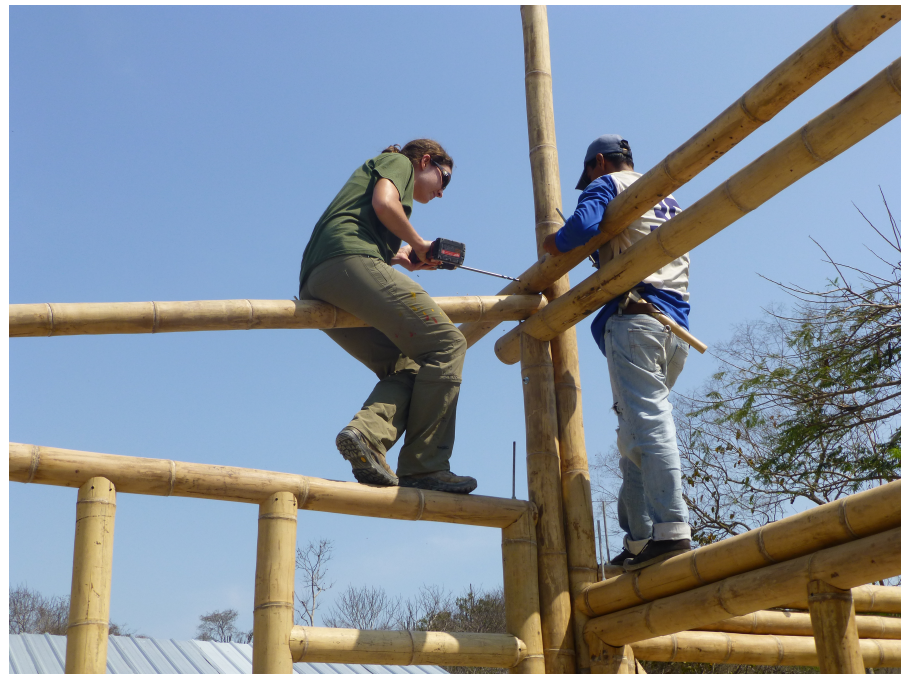

Bamboo (specifically Guadua) is native to Ecuador and plentiful. There are treatment plants all throughout the country. After now having built many houses, BBC has plans to start a bamboo farm. The area around Bahia has been devastated by deforestation. This loosens the soil and causes more landslides and more destruction during earthquakes especially. This is a perfect place for bamboo because bamboo actually rejuvenates soil as it grows. Also, when bamboo is harvested it doesn't die. The roots will sprout new bamboo. Learning about bamboo in different contexts (both at UA and at BBC) has given our student a very good understanding of the plant and its potential as a renewable resource.

An aspect that made this trip truly incredible was the interaction with so many community members throughout the program. The students in the program added a bamboo bench to a neighbor's yard. They helped build the program cook's new bathroom. They painted a bamboo house for a family whose 2 story home was flattened during the earthquake, actually trapping them for a few minutes. Meeting and engaging with community members helped the students understand the culture of these people and gave them a glimpse of their day to day lives. This experience gave students in the program the feeling they were truly making a difference. 
While our student studied framing systems during her summer at UA, the approaches for research are different than what was used in building homes in this earthquake devastated community. In Ecuador, the student participants used bolted connections and screws. During her summer REU, our student wanted to do something similar but was worried that drilling through the small culms used in research would cause them to split thus resulting in a loss of strength. The bamboo culms in Ecuador were bigger in diameter and if drilled through slowly, do not split. Another aspect our student struggled with in the summer REU, was finding an adequate method to attach the

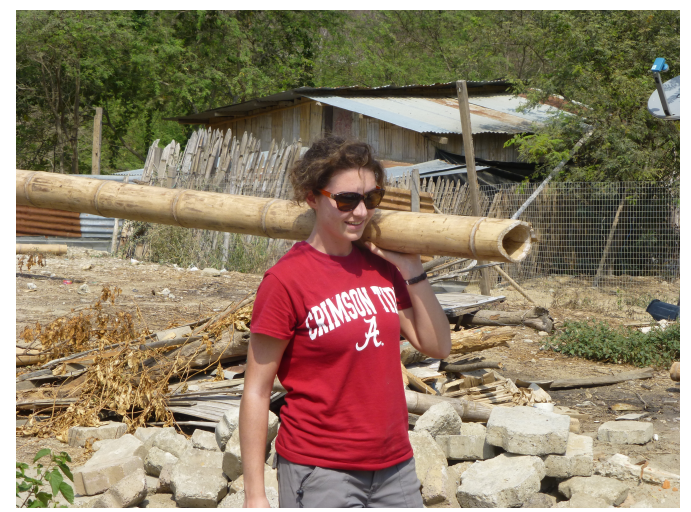
bamboo frames to the shake table. Strap ties were very flexible and affected their test results. In

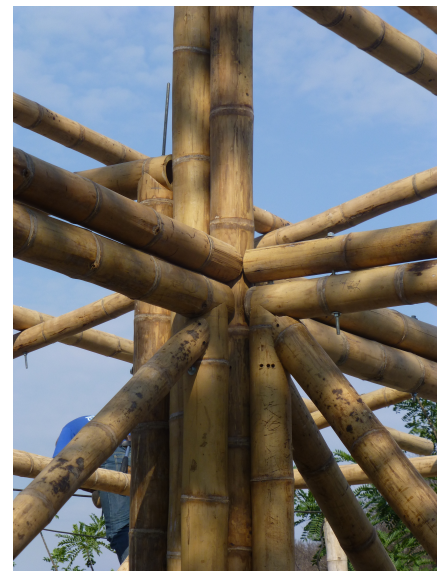
practicality, the bamboo house's foundation is concrete and rebar comes up from the floor to hold each bamboo column in place.

UA's entrepreneurship program, Crimson Startup, provided our student knowledge about the customer discovery process (interviewing potential customers to help refine product designs) and creating a basic Business Model. In the BBC program, she learned about businesses having social and environmental responsibility. This helped her branch off of the basic model to learn about a variety of business types such as Social Enterprises, Benefit Corporations, and NGOs. Having the business model knowledge from the summer program at UA allowed her to gain a deeper understanding of the importance of a business model and to ask more complex questions while learning about business in the BBC Program.

\section{Assessment}

The REU students complete confidential online surveys at the beginning (pre-site), middle, and end (postsite) of their summer REU experience. They also participate in a focus group discussion at the end of the summer and another online survey nine months later (follow-up) near the end of the following academic year. These surveys and the focus group assess a wide range of issues including overall satisfaction with the program, satisfaction with specific features of the program, knowledge gains and development of technical skills, feelings of personal fit within engineering, attitudes toward research, and interest in graduate education. For this paper we were most interested in students' attitudes toward research in general and the value and importance of research, especially as it relates to renewable resources, the primary topic area of the REU. Data for the first two years of the program (10 students in 2016 and 9 in 2017) are included in the analysis. In addition to the quantitative results from close-ended survey questions, the comments made by the students in response to open-ended questions, both in the focus group and on their surveys, provide additional insight into their reflections on the impact of the REU and their interest in the research topic and research in general.

\section{Satisfaction}

Overall, the students have been happy with the REU experience, and good post-site ratings for the first year became even better in the second year. These ratings are presented in Table 1. Students who gave relatively lower ratings tended to be those who had less interaction with or direction from their mentors. Students who said "maybe" they would recommend the program indicated that a lot depended on the mentor and a person's level of interest in research. 
Table 1. Satisfaction with the REU

\begin{tabular}{|c|c|c|}
\hline Post-site & 2016 & $2017^{a}$ \\
\hline $\begin{array}{l}\text { Satisfaction with the program overall } \\
\text { 1-Extremely satisfied } \\
\text { 2-Somewhat satisfied } \\
\text { 3-Neutral } \\
\text { 4-Somewhat dissatisfied } \\
\text { 5-Extremely dissatisfied } \\
\text { Mean }\end{array}$ & $\begin{array}{c}3 \\
5 \\
1 \\
1 \\
0 \\
2.0\end{array}$ & $\begin{array}{c}6 \\
0 \\
0 \\
0 \\
0 \\
1.0\end{array}$ \\
\hline $\begin{array}{l}\text { Satisfaction with research experience overall } \\
\text { 1-Extremely satisfied } \\
\text { 2-Somewhat satisfied } \\
\text { 3-Neutral } \\
\text { 4-Somewhat dissatisfied } \\
\text { 5-Extremely dissatisfied } \\
\text { Mean }\end{array}$ & $\begin{array}{c}3 \\
2 \\
2 \\
2 \\
1 \\
2.6\end{array}$ & $\begin{array}{c}5 \\
1 \\
0 \\
0 \\
0 \\
1.2\end{array}$ \\
\hline $\begin{array}{l}\text { Satisfaction with research project topic } \\
\text { 1-Extremely satisfied } \\
\text { 2-Somewhat satisfied } \\
\text { 3-Neutral } \\
\text { 4-Somewhat dissatisfied } \\
\text { 5-Extremely dissatisfied } \\
\text { Mean }\end{array}$ & $\begin{array}{c}4 \\
4 \\
2 \\
0 \\
0 \\
1.8\end{array}$ & $\begin{array}{c}3 \\
3 \\
0 \\
0 \\
0 \\
1.5\end{array}$ \\
\hline $\begin{array}{l}\text { Would you recommend this program to others? } \\
\text { Yes } \\
\text { Maybe } \\
\text { No }\end{array}$ & $\begin{array}{l}7 \\
3 \\
0\end{array}$ & $\begin{array}{l}6 \\
0 \\
0\end{array}$ \\
\hline
\end{tabular}

${ }^{a}$ In 2017, six of the nine students completed the post-REU survey. Although we recognize this as a limitation that has the potential to introduce bias, we found on the mid-summer survey that all nine students agreed they were satisfied with the program overall and they were having a good research experience. Furthermore, in a focus group conversation, all nine of the students expressed that they had a positive experience in the REU. Thus, it does not seem likely that the three students who did not complete the post-REU survey were substantially less satisfied than those who did complete the survey.

In both years, the open-ended comments of the students were very positive and complimentary about the program overall. They felt it provided them with research opportunities that were not available at their home institutions, and they were enthused about the focus on bamboo and renewable resources. They appreciated the opportunities to learn new information and skills as well as reinforce and enhance skills they already possessed. Following are some of the comments recorded when students were asked what factors contributed to their positive feelings about the program or what they liked about the program.

- The REU program was a beneficial learning experience for me, for it provided me with knowledge about a subject I had little background in and taught me about the experience of research. Overall, it has made me into a more well-rounded person.

- I think that this program really opened up my eyes to what bamboo can be used for as a renewable resource. . . really great opportunity to explore the area and learn more on how our research can be applicable to the real world.

- The topic of the REU was important - renewable aspect and a cutting edge area.

- I enjoyed getting to work with my professor and I feel more confident with my research skills as far as organizing, planning, and collecting and managing data go.

Attitudes toward research

Students' feelings about the importance of research and their interest in research did not change dramatically over the summer, primarily because most students came to the program with positive 
feelings in this regard. Their knowledge of research with bamboo and renewable resources did increase substantially. On all of these variables, post-site ratings were more positive in 2017 than in 2016.

Table 2. Attitudes toward research

\begin{tabular}{|c|c|c|c|c|}
\hline & \multicolumn{2}{|c|}{2016} & \multicolumn{2}{|c|}{2017} \\
\hline & Pre-site & Post-site & Pre-site & Post-site \\
\hline Your feeling about scientific and engineering research & & & & \\
\hline 1-Exciting & 5 & 3 & 4 & 4 \\
\hline 2-Interesting & 5 & 5 & 5 & 2 \\
\hline 3-Neutral & 1 & 1 & 0 & 0 \\
\hline 4-Mundane & 0 & 1 & 0 & 0 \\
\hline 5-Boring & 0 & 0 & 0 & 0 \\
\hline Mean & 1.6 & 2.0 & 1.6 & 1.3 \\
\hline $\begin{array}{l}\text { I place a high value on the role of research in my future } \\
\text { career. }\end{array}$ & & & & \\
\hline 1-Strongly agree & 3 & 2 & 1 & 2 \\
\hline 2-Agree & 1 & 4 & 4 & 2 \\
\hline 3-Neutral & 5 & 2 & 3 & 2 \\
\hline 4-Disagree & 1 & 1 & 1 & 0 \\
\hline 5-Strongly disagree & 0 & 1 & 0 & 0 \\
\hline Mean & 2.4 & 2.5 & 2.4 & 2.0 \\
\hline $\begin{array}{l}\text { Research in engineering is important for identifying } \\
\text { problems and solutions to society. }\end{array}$ & & & & \\
\hline 1-Strongly agree & 6 & 2 & 5 & 4 \\
\hline 2-Agree & 4 & 7 & 4 & 2 \\
\hline 3-Neutral & 0 & 0 & 0 & 0 \\
\hline 4-Disagree & 0 & 0 & 0 & 0 \\
\hline 5-Strongly disagree & 0 & 0 & 0 & 0 \\
\hline Mean & 1.4 & 1.8 & 1.4 & 1.3 \\
\hline $\begin{array}{l}\text { I am committed to applying engineering to the benefit of } \\
\text { society. }\end{array}$ & & & & \\
\hline 1-Strongly agree & 8 & 4 & 8 & 4 \\
\hline 2-Agree & 1 & 5 & 1 & 2 \\
\hline 3-Neutral & 1 & 0 & 0 & 0 \\
\hline 4-Disagree & 0 & 0 & 0 & 0 \\
\hline 5-Strongly disagree & 0 & 0 & 0 & 0 \\
\hline Mean & 1.3 & 1.6 & 1.1 & 1.3 \\
\hline How likely to pursue professional career in research & & & & \\
\hline 1-Very likely & 1 & 2 & 0 & 0 \\
\hline 2-Somewhat likely & 2 & 1 & 4 & 4 \\
\hline 3-Neither & 5 & 3 & 4 & 2 \\
\hline 4-Somewhat unlikely & 1 & 1 & 1 & 0 \\
\hline 5-Very unlikely & 1 & 3 & 0 & 0 \\
\hline Mean & 2.9 & 3.2 & 2.7 & 2.3 \\
\hline Knowledge of bamboo and renewable resources & & & & \\
\hline 1-Excellent & 0 & 3 & 0 & 2 \\
\hline 2-Good & 3 & 4 & 3 & 4 \\
\hline 3-Average & 2 & 1 & 4 & 0 \\
\hline 4-Fair & 3 & 2 & 1 & 0 \\
\hline 5-Poor/Nonexistent & 2 & 0 & 1 & 0 \\
\hline Mean & 3.4 & 2.2 & 3.0 & 1.7 \\
\hline
\end{tabular}

On the pre-site survey, students were asked about the importance of a variety of issues in their decision to participate in this specific REU site, such as geographic location, university reputation, amount of the stipend, etc. Among these issues were, "working in this particular field of research (bamboo and 
renewable resources)" and "the research project sounds interesting." As shown in Table 3, for most students, these two factors were "extremely" or "very" important in their decision making.

Table 3. Importance of the research content for decision about REU

\begin{tabular}{|l|c|c|}
\hline Pre-site & $\mathbf{2 0 1 6}$ & $\mathbf{2 0 1 7}$ \\
\hline Working in this particular field of research & & \\
1-Extremely important & 4 & 4 \\
2-Very important & 4 & 2 \\
3-Moderately important ${ }^{\mathrm{a}}$ & 2 & 2 \\
4-Not important at all & 0 & 1 \\
Mean & 1.8 & 2.0 \\
\hline The research project sounds interesting $^{\mathrm{a}}$ & & \\
1-Extremely important & 4 & 5 \\
2-Very important & 4 & 0 \\
3-Moderately important & \\
4-Not important at all & 2 & 0 \\
Mean & 0 & 1.4 \\
\hline
\end{tabular}

an 2016, these choices were labeled "2-fairly important" and "3-somewhat important."

For some students, however, the project was actually not as interesting as they might have expected. Postsite ratings of the research project showed some variation, especially in 2016, when several students found their project to be only "moderately" or "slightly" interesting.

Table 4. Research project was interesting

\begin{tabular}{|l|c|c|}
\hline Post-site & $\mathbf{2 0 1 6}$ & $\mathbf{2 0 1 7}$ \\
\hline How interesting was your research project? & & \\
1-Extremely interesting & 2 & 1 \\
2-Very interesting & 2 & 4 \\
3-Moderately interesting & 3 & 1 \\
4-Slightly interesting & 3 & 0 \\
5-Not interesting at all & 0 & 0 \\
Mean & 2.7 & 2.0 \\
\hline
\end{tabular}

Explanations for their ratings differed somewhat between the two years. In 2016, the more positive ratings were explained by comments such as: exciting to be part of a developing field of science, was in student's field of interest; while those who found it less interesting said: research was very simple, not able to do what was planned, research not in student's field of interest. In 2017, the explanations given were more enthusiastic:

- I thought it was cool that bamboo could be applied into so many different fields. Before coming for the summer, I had no idea that was possible!

- It was interesting to me as I have always been interested in renewable resources and their application toward the civil engineering world.

- The research that I went into is useful, to avoid destructive testing of bamboo. It was interesting to learn the biology of the bamboo and the electrical and thermal effects on it.

The students were asked specifically how their knowledge of or perspective on bamboo and renewable resources had changed over the summer. Their responses indicate a broadening of their views on renewable resources and appreciation for research on alternatives to standard materials.

- I know now that there are plenty of other unorthodox renewable resources out there for numerous different applications. 
- I know now there are many different applications for bamboo that are related and can be researched by all different fields of engineering.

- It has changed my perspective on how to be more creative and realistic with ways to replace resources with more renewable and sustainable alternatives.

- Learning about bamboo, I gained an idea of how broadly it is used! I was pleased to learn that bamboo is a widely used and increasingly popular material to be used for construction.

- Obscure materials need to be studied.

- I learned a lot about bamboo ... has helped give me a lot of interest in seeing bamboo used in the future and I really would like to incorporate it into more of modern society if possible.

- There are many opportunities to use bamboo as a building material.

- I will be on the lookout for further developments in this new US industry.

- I now see value in bamboo

- I had not previously thought much about bamboo, but after this program, it seems like there are an endless number of possibilities, and it is definitely going to be increasingly important in the future.

Three additional items from the post-site survey shed light on the impact of the REU on students' understanding of engineering research and views of a research career. Students appeared to be more positive after the 2017 REU than the previous year regarding the impact of the experience on their ability to do research in the future.

Table 5. Impact of REU on views of research

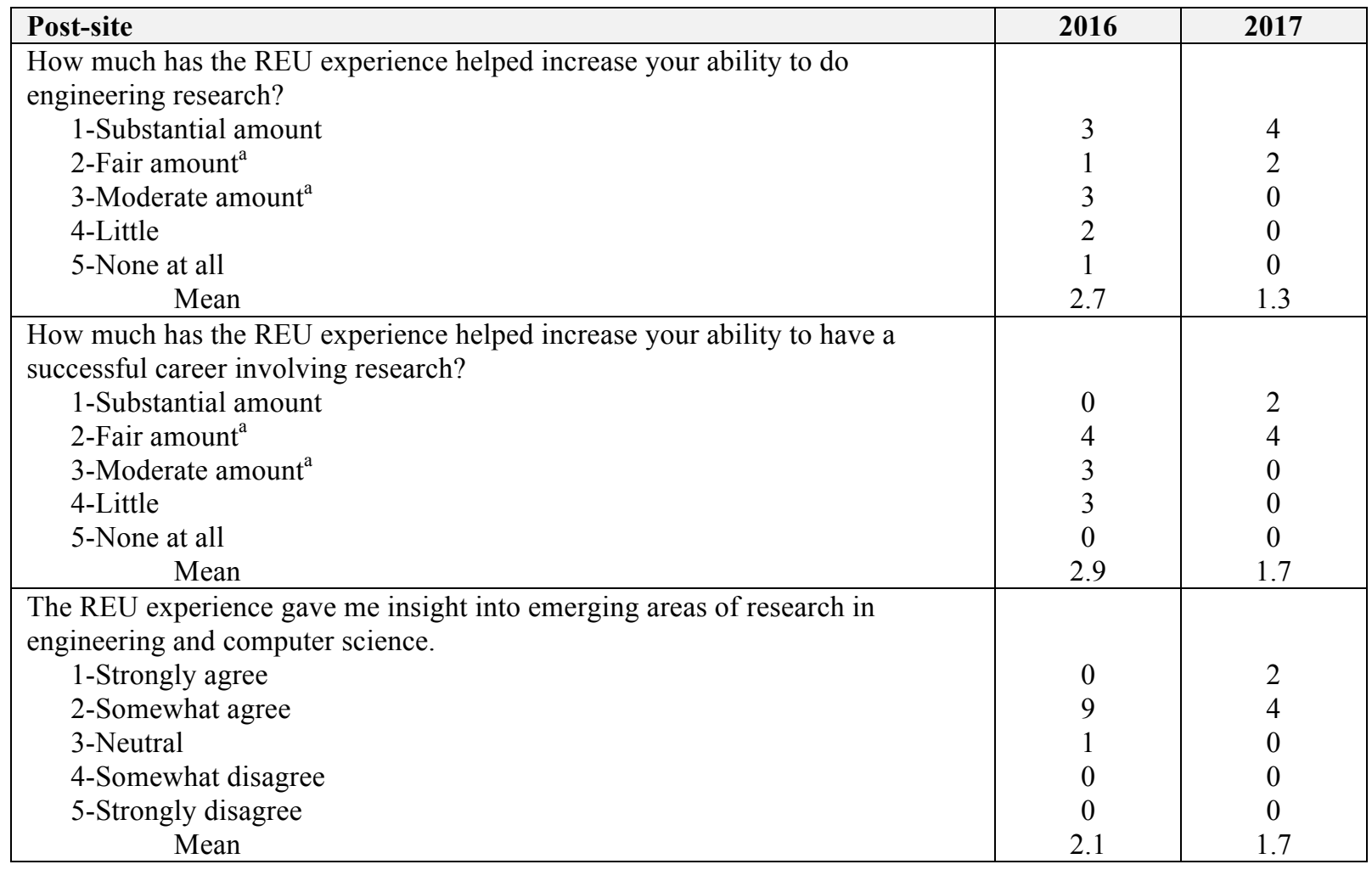

an 2016, these choices were labeled "2-good amount" and "3-satisfactory amount."

The final question on the post-site survey asked the students what they had learned about themselves during the summer experience. In 2017, five of the six respondents said specifically that they learned they like research, which fits exactly what the REU is designed to do. In 2016, some of the students had 
struggled a bit more. Their comments indicated that several learned about their ability to be more independent than they thought, one discovered a stronger work ethic than expected, one identified a need to work on self-motivation, and one learned of the capability of doing research.

In conclusion, the students expressed appreciation of the social value of renewable resources in general and bamboo specifically, and many were attracted to the REU particularly because of its emphasis on bamboo and renewable resources. Their knowledge about bamboo and renewable resources increased, and they felt the experience contributed to their understanding of and ability to conduct engineering research. Ratings for the second year of the program were generally even more positive than those of the first year, as adjustments were made and several changes were implemented. Most students in the first year and all students in the second year reported having a very good experience and would recommend the REU to other students.

\section{Summary}

REU Sites offer students the ability to engage in research while picking up other skills that will benefit their future career choices. An international experience is described in this paper that complements a 2017 student participant's experience who conducted research on the seismic performance of building materials. This project led her to a unique program in Ecuador where she could interact with architects and master builders who were helping a community rebuild homes after a devastating earthquake. Her REU experience put her in an excellent position to contribute to this international program and reinforced knowledge she gained about bamboo, applications that leverage bamboo properties, entrepreneurship, and community engagement.

Acknowledgments: The authors acknowledge NSF EEC-1559867 for funding. In addition, we are grateful to the Bahia Beach Construction (BBC) program for offering students an incredible opportunity for experiential learning.

\section{References}

1. S. L. Burkett, T. E. Dye, and P. D. Johnson, "REU - NAE Grand Challenges Site at the University of Alabama," American J. Eng. Education, Vol. 6, No. 2, pp. 125-134, December 2015.

2. W. J. Gonzalez-Espada and D. S. LaDue, "Evaluation of the Impact of the NWC REU Program Compared with Other Undergraduate Research Experiences," J. Geoscience Educ., Vol. 54, No. 5, pp. 541-549, 2006.

3. A. L. Zydney, J. S. Bennett, A. Shahid, and K. W. Bauer, "Iimpact of Undergraduate Research Experience in Enginering," J. Eng. Educ., Vol. 91, No. 2, pp. 151-157, 2002.

4. https://www.bahiabeachconstruction.com/

5. T. Dahlberg, T. Barnes, A. Rorrer, E. Powell, and L. Cairco, "Improving Retention and Graduate Recruitment through Immersive Research Experiences for Undergraduates," SIGCSE Proc. $39^{\text {th }}$ Technical Symp. on Computer Science Education, pp. 466-470, Portland, OR, 2008.

6. http://icorps.ua.edu/crimson-startup.html

7. https://venturewell.org/lean-launchpad/

8. S. L. Burkett, E. R. Giannini, R. M. Frazier, D. M. McCallum, S. G. Wood, and G. Quenneville, "Entrepreneurial Training for REU Students," Proc. ASEE Southeast Regional Conference, San Juan, Puerto Rico, 2017.

9. G. Ragusa, C. Matherly, and S. Phillips, "Comparison of the Impact of Two Research Experiences for Undergraduate Programs on Preparing Students for Global Workforces," Proc. IEEE FIE Conf., Oct. 22-25, Madrid, Spain, 2014. 
